\title{
Mechanical behavior of ultrafine-grained/nanocrystalline titanium synthesized by mechanical milling plus consolidation: experiments, modeling and simulation
}

\author{
Jian Liu ${ }^{\mathrm{a}}$, Akhtar S. Khan ${ }^{\mathrm{a}}$, Laszlo Takacs ${ }^{\mathrm{b}}$, Christopher S. Meredith ${ }^{\mathrm{a}}$ \\ a. Department of Mechanical Engineering, University of Maryland, Baltimore County, Baltimore, MD 21250, USA \\ b. Department of Physics, University of Maryland, Baltimore County, Baltimore, MD 21250, USA
}

\begin{abstract}
High quality bulk ultrafine-grained/nanocrystalline titanium samples were prepared through room temperature mechanical milling and conventional consolidation processes. The prepared bulk samples showed high purity, very low porosity and high ductility under compression. The dependency of yield stress and post-yielding behavior on grain size, strain rate and temperature were comprehensively studied. The texture evolution of the ufg/nc samples under compression was measured by synchrotron XRD. On the macroscopic scale, the viscoplastic phenomenological Khan-Liang-Farrokh (KLF) model was used to correlate the experimental results of the ufg/nc Ti.
\end{abstract}

Keywords: mechanical milling, ultrafine grained/nanocrystalline, commercial purity titanium, strain rate sensitivity, texture 


\section{Introduction}

Titanium and titanium alloys are used in many applications, ranging from aerospace engineering to biomedical technology. Unalloyed commercially pure (CP) Ti has advantages such as corrosion resistance, inertness and biocompatibility over commonly used $\mathrm{Ti}$ alloy. However, the use of $\mathrm{CP}$ Ti has been limited due to its relatively low strength. One of the approaches available for improving the strength of $\mathrm{CP} \mathrm{Ti}$ is the refinement of the grain size. According the Hall-Petch relationship, decreasing grain size leads to increasing yield strength. Numerous experimental investigations have demonstrated that the strength and hardness of metals with ultra-fine grains (ufg, $100 \mathrm{~nm}<$ grain size $<1 \mu \mathrm{m}$ ) or nanocrystalline grains (nc, grain size $<100 \mathrm{~nm})$ are significantly enhanced over those of their coarse-grained (cg) counterparts.

Since its introduction into modern science as a major field by Gleiter (1989), ufg/nc materials have been the subject of widespread research (Jia et al., 2001; Meyers et al., 2006; Valiev et al., 2008; Khan et al., 2008a, 2008b; Barai and Weng, 2009; Farrokh and Khan, 2009; Meredith and Khan, 2012; Feng et al., 2013; Kumar et al., 2013; Okamoto et al., 2014; Ivanisenko et al., 2014). Many methods have been developed to synthesize materials with ufg or nc grain size, including inert gas condensation, electro-deposition, crystallization from amorphous material, severe plastic deformation and mechanical milling (including cryomilling) (Meyers et al., 2006).

Although each method has its advantages and disadvantages, SPD and mechanical milling stand out as versatile techniques to synthesize ufg/nc materials. They are both capable of producing ufg/nc structures in almost any type of material and in large quantities. They also require relatively inexpensive equipment. 


\section{$1.1 \mathrm{ufg} / \mathrm{nc} \mathrm{Ti}$ in literature}

Most reported studies on the preparation of ufg/nc pure $\mathrm{Ti}$ employed severe plastic deformation (SPD) techniques. SPD processes can refine the grain size without introducing porosity or extra impurities by subjecting the bulk samples to exceptionally high strains.

The Equal Channel Angular Pressing (ECAP) is the most promising and well-studied SPD technique. The advantage of ECAP is its capability to maintain the net dimensions of the workpiece. Based on the experimental data (Zhernakov et al., 2001; Stolyarov et al., 2001; Tabachnikova et al., 2005; Ko et al., 2006; Shpeǐzman et al., 2007; Korshunov et al., 2008; Hyun et al., 2010; Meredith and Khan, 2012), it can be concluded that after multiple passes of ECAP at different conditions, the grain size can be decreased to $200-300 \mathrm{~nm}$ which leads to a 1.2- to 2.6fold increase of the yield stress and tensile ultimate strength. The tensile ductility after ECAP was in the $10-20 \%$ range, which was sufficient for structural application. The value of the enhanced yield and ultimate strength depends not only on the processing parameters but also on the purity of the material. The yield strength of ECAPed pure Ti was in the range of 450-800 $\mathrm{MPa}$ whereas the ultimate strength was in the range of 660-820 MPa. By comparison, the strength of ECAPed pure Ti was lower or barely equal to that of Ti-6Al-4V alloy. This limitation of strength enhancement correlates closely with the limited grain size refining capability of the ECAP process.

In order to further increase the strength, a large number of investigations have applied additional cold working or SPD processes after the ECAP processing on CP Ti (Jia et al., 2001; Stolyarov et al., 2003; Zhu et al., 2003; Sadikova et al., 2005; Latysh et al., 2006; Salimgareeva et al., 2006; Semenova et al., 2008; Valiev et al., 2008). These processes can further refine the 
grain size/microstructure and/or introduce more dislocations to improve the strength. Strengths above $1 \mathrm{GPa}$ can be obtained, which are higher than the strength of common Ti-6Al-4V alloys.

Other SPD techniques such as high-pressure torsion (HPT) (Popov et al., 1997; Sergueeva et al., 2001), accumulative roll-bonding (ARB) (Terada et al., 2007), hydrostatic extrusion (HE) (Garbacz et al., 2006; Pachla et al., 2008; Topolski et al., 2010), cryorolling (Moskalenko et al., 2009), etc. were also used (without ECAP) to refine the grain size and enhance the strength. A combination of high strength and sufficient ductility was achieved in those cases. However, unlike ECAP, the other SPD techniques, used either by themselves or in combination with ECAP, do not preserve the dimensions of the workpiece. One or more dimensions of the workpiece are continuously reduced, which eventually reduces the workpiece to a final geometry of foil/plate or small diameter rod/wire, limiting their structural application.

Although there were several studies on the ball milling of Ti powder and the characterization of the milled powder (Wang et al., 1993; Panigrahi and Godkhindi, 2006; Dabhade et al., 2001, 2006; Sun et al., 2006a, 2006b), very few researchers produced bulk ufg/nc Ti samples using ball-milling plus consolidation. Among those, only the research group of Enrique J. Lavernia (Ertorer et al., 2008, 2009, 2010) obtained bulk fully dense samples of large enough sizes for experimental measurements of the plastic behavior. They used cryomilling as the milling process and hot quasi-isostatic forging (QIF) (Ertorer et al., 2008, 2009) or spark plasma sintering (SPS) (Ertorer et al., 2010) as the consolidation method. These techniques require more expensive equipment and are harder to scale-up to industrial applications compared to the room temperature milling and conventional hot compaction used in this study. Also, to maintain the ductility, they intentionally mixed the milled nano Ti powder with un-milled powder to achieve a bimodal grain size distribution for most of their samples. As a result, the yield strength and 
ultimate tensile strength are only comparable to those obtainable by ECAP and are lower than those obtained by other SPD techniques.

In summary, ECAP could refine the grain size of Ti without reducing the dimensions of the samples. However, due to the limitation of grain size refinement (200-300 $\mathrm{nm}$ ) by ECAP, the increase of strength of Ti is limited (below $1 \mathrm{GPa}$ ). Other SPD techniques could further refine the grain size and/or the microstructure and increase the strength (above $1 \mathrm{GPa}$ ). However, one or more dimensions of the workpiece are continuously reduced, limiting their structural applications.

In the rather limited literature on ufg/nc Ti by mechanically milling and consolidation, no researchers have used room temperature milling and conventional hot compaction to produce fully dense bulk samples. Also, mechanical milling's ability of grain size refinement (into nano range, below $100 \mathrm{~nm}$ ) and strengthening (above $1 \mathrm{GPa}$ ) are not fully exploited. This study fills these voids in the existing research.

\subsection{Deformation mechanisms of Ti}

Unalloyed commercially pure (CP) titanium is a $\mathrm{HCP}$ metal with a c/a ratio of 1.588 which is lower than the ideal value of 1.633. For Ti, the easiest deformation mode (mechanism) is prismatic slip which means prismatic slip will be the first to be activated when the random textured material enters plastic deformation. With further straining and increasing stress, other deformation modes such as basal slip, pyramidal $\langle a\rangle$ slip, pyramidal $\langle c+a\rangle$ slip, tensile and compressive twinning could also be activated. Especially when there is a strain component along the c-axis of a grain, at least one deformation mode-the pyramidal $\langle c+a\rangle$ slip and/or twiningneeds to be active to accommodate it. Although the prismatic slip is the easiest to activate, the plastic deformation of $\mathrm{Ti}$ is the result of the competition among prismatic, basal, pyramidal $\langle a\rangle$, 
pyramidal $\langle c+a\rangle$ slip and twinning. At the grain level, the relative contribution from each deformation mode is determined by the relative strength of each slip/twining system and the orientation of the grains with respect to the loading direction.

Generally, the strength of each deformation mode is affected by the temperature, strain rate, solute concentration, grain size, etc. An increase of solute concentration and a decrease of grain size are expected in Ti processed by mechanical milling and consolidation. By investigating the mechanical responses (macroscopic stress-strain curves) and texture evolutions of the ufg/nc $\mathrm{Ti}$ under plastic deformation, it is possible to find out the operative deformation mechanisms at the $\mathrm{ufg} / \mathrm{nc}$ grain size. As a result, the effect of ufg/nc grain size on the deformation mode of $\mathrm{HCP} \mathrm{Ti}$ can be studied.

\subsection{Objective and outline}

In this research project the mechanical milling technique is applied to prepare $\mathrm{ufg} / \mathrm{nc}$ commercially pure Ti. The successful synthesis of bulk fully dense ufg/nc Ti sample makes subsequent studies of the mechanical properties, deformation mechanisms, microstructure etc. possible.

The first objective of this research project is to improve the preparation technique used by Khan et al. (2000a, 2000b \& 2006) and optimize the process variables for the synthesis of ufg/nc $\mathrm{CP} \mathrm{Ti}$, so that this ball milling plus consolidation technique can be used to prepare high quality bulk samples, capable of undergoing large plastic strains, with proper sizes suitable for mechanical experiment.

The second objective is to study the mechanical properties of the prepared $u f g / n c \mathrm{CP} \mathrm{Ti}$ samples. The dependency of yield stress and post-yielding behavior on grain size, strain rate, and 
temperature are to be studied. Also, the texture evolution will be studied which will give some indications on the operative deformation mechanisms of ufg/nc Ti.

The third objective is to use a grain size and temperature dependent visco-plastic constitutive model (KLF model) to simulate the post-yield behavior of the material.

\section{Experimental Procedures}

\subsection{Mechanical milling procedures}

The Ti powder (-100 mesh, 99.4\% pure) was obtained from Alfa Aesar®. The powder was first degassed and dried under vacuum at $520 \mathrm{~K}$ for 7 hours.

The milling container and milling medium were $500 \mathrm{ml}$ steel vials and hardened steel balls (12.5 $\mathrm{mm}$ in diameter), respectively. All material handling was performed in a glove box filled with argon with the oxygen impurity level maintained below $3 \mathrm{ppm}$. With a ball-to-powder ratio of 16:1, 60 steel balls ( $480 \mathrm{~g}$ ), $30 \mathrm{~g}$ of Ti powder and a small amount of process control agent (PCA) were loaded into each milling vial and the milling vials were then sealed inside the glove box. The sealed vials were never opened until the end of the milling process. The use of the glove box is very important as it keeps the powder away from contact with air during the entire process so that oxygen and hydrogen contamination from the air can be minimized.

Ball milling was accomplished using a Fritsch Pulverisette-5 planetary mill. The speed of the mill was set to $120 \mathrm{rpm}$. Milling was carried out at room temperature and 15 minutes of milling was alternated with 15 minutes of cooling in order to avoid a significant temperature increase. In order to obtain powders with different grain sizes, milling times of 5, 10, 15 and 20 hours were used. As a result of the heavy plastic deformation during milling, the powder particles get cold welded to each other and the milling medium. To obtain enough yield of powder for the 
subsequent consolidation, small amounts of stearic acid $\left(\mathrm{CH}_{3}\left(\mathrm{CH}_{2}\right)_{16} \mathrm{COOH}\right)$ were added to the powder to serve as surface-active process control agent (PCA) to minimize the cold-welding. The stearic acid adheres to the surface of powder particles, reduces the effect of excessive cold welding and inhibits powder agglomeration (Suryanarayana, 2001). The amount of PCA was 0.2, $0.4,0.6$ and 0.8 wt. \%, for 5, 10, 15 and 20 hours milling time, respectively.

\subsection{Consolidation procedures}

In order to obtain ufg/nc Ti in bulk form, the milled powder was removed from the vials after milling and loaded into a hollow cylindrical die inside the glove box. The die consisted of three components all made of heat-treated Vasco-Max C350: 1.) a cylindrical die with inner and outer diameters of 22 and $54 \mathrm{~mm}$, respectively; 2.) a cylindrical split die which allowed the easy removal of the specimen from the die after consolidation; 3.) two plungers to consolidate the powder from the top and bottom simultaneously (Khan et al., 2008b). The inner cylindrical split inserts were lubricated using Teflon ${ }^{\circledR}$ spray to reduce the effect of friction forces during the consolidation process.

The powder was pre-cold-compacted inside the glove box using a 4-ton bottle jack. The initial green body resulting from the pre-compaction process was isolated by thin layers of graphite powder on both ends. This was done to prevent the penetration of oxygen and other impurities during the subsequent fabrication processes carried out outside the glove box. The initial green body was subjected to higher compacting pressure at room temperature for several minutes, followed by compaction at an elevated temperature under axial pressure. After warm compaction the sample was removed from the die and subjected to additional heat treatment. The objective was to achieve higher density, eliminate adsorbents and enhance proper inter-particle bonding in the samples. The detailed parameters of the consolidation process are given in Table 
1. Using this technique, bulk specimens were prepared from the consolidation of the as-received powder and powders milled for 5, 10, 15 and 20 hours.

\subsection{Uniaxial quasi-static compression experiments}

Uniaxial quasi-static compression experiments were performed at different strain rates and temperatures using a MTS 809 Axial/ Torsional Material Testing System. Rectangular prism compression specimens with nominal dimensions of $4.24 \mathrm{~mm} \times 4.24 \mathrm{~mm} \times 6.35 \mathrm{~mm}$ were cut in such a way that the loading direction of the compression experiment is perpendicular rather than parallel to the compaction direction of the powder consolidation. A uniaxial strain gage, of type KFEL-2-120-C1 (2 mm gage length) by Kyowa Electronic Instruments was used during each room-temperature experiment. At temperatures other than room temperature, strain gages were not used. The "blank test" data, which provided the displacement of only the machine, platen, and lubricant, was used to correct the strain for the experiments. Teflon sheets and Dow Corning high vacuum grease were applied to the top and bottom platens to reduce friction and to maintain uniform uniaxial stress state.

\subsection{Uniaxial dynamic compression experiments}

The split-Hopkinson pressure bar technique (SHPB) was used to perform dynamic uniaxial compression experiments on samples that were made from 10 hours milled powder, at an engineering strain rate of about $1500 \mathrm{~s}^{-1}$. The pressure bars were made out of 0.5 inch diameter Vascomax C350 maraging steel. The high strain rate specimens were rectangular prism ones with nominal dimensions of $6.35 \mathrm{~mm} \times 6.35 \mathrm{~mm} \times 3.56 \mathrm{~mm}$, which corresponds to a length to side ratio of 0.56. More details of the SHPB technique were given in Khan and Liang (1999), Khan and Zhang (2000), Khan et al. (2004) and Khan et al. (2007). 


\subsection{Texture and grain size measurement by XRD technique}

Synchrotron X-Ray diffraction (SXRD) was used to measure the grain size and texture of Ti samples. The synchrotron XRD has much higher energies than XRD using a $\mathrm{Cu}$ or Mo tube source, thus the X-ray beam passes through the sample and the detector is behind the sample. The measured patterns are characteristics of the bulk of the sample, rather than its surface, as is in the case of low energy XRD performed in reflection. Synchrotron X-ray diffraction (XRD) was utilized at the Advanced Photon Source (APS) at Argonne National Laboratory using beamline 11-ID-C. In each SXRD measurement, a Laue pattern was recorded. The raw pole figures were analyzed using the MAUD program (Wenk et al., 2003). The intensity differences of the Laue patterns were integrated to give the peak profiles. The peak profiles were then used to calculate the average grain sizes for each sample. The peak profiles were evaluated using MAUD which is mainly based on the Rietveld method. Initially, the diffraction profile of a standard sample ( $\mathrm{CeO} 2$ in this case) is recorded to determine instrument parameters which are refined and remain fixed for subsequent analysis of the titanium of interest. Once the instrument broadening was corrected for, the remaining peak broadening is assumed mostly from the contribution of the grain size and the microstrain. The grain size and microstrain parameters were refined (along with others) to obtain a best fit.

The textures of un-deformed (as-prepared) samples were measured on the plane which is perpendicular to the compaction direction of the consolidation process.

The textures of deformed samples were measured on the plane which was perpendicular to the loading direction of the compression experiments. One thing to emphasize is that the loading direction of the compression experiment is perpendicular instead of parallel to the compaction direction of the powder consolidation. 


\section{Results and Discussion}

\subsection{Characteristic of bulk ufg/nc Ti}

The density of the bulk samples was measured to be more than $98 \%$ of the theoretical density which meant that the consolidation process was efficient in consolidating ball milled Ti powders into almost full density bulk specimens.

From the SXRD measurements, the grain size of the bulk samples prepared from powders of $5,10,15$ and 20 hours milling periods are $107,82,58,43 \mathrm{~nm}$, respectively.

\subsection{Thermo-mechanical properties}

\subsubsection{Milling time effect}

Figure 1 illustrates the results from room temperature uniaxial compression experiments at a strain rate of $10^{-4} \mathrm{~s}^{-1}$ on specimens prepared from as-received (un-milled), 5, 10, 15 and 20 hours milled powders. It is evident that the yield strength increases dramatically as the milling time is increased. The change is about 4-fold, from $\sim 500 \mathrm{MPa}$ for the sample from un-milled powder to 1800 MPa for the sample from 20 hours milled powder. Samples from un-milled powder and 5 hours milled powder have a yield stress of $\sim 500 \mathrm{MPa}$ and $\sim 950 \mathrm{MPa}$, respectively; both can be compressed to large strains (>60\%) without any sign of failure. Samples from 15 and 20 hours milled powder fail at a strain of $\sim 14 \%$ and $\sim 8 \%$, respectively. The decreases of ductility occur possibly due to higher strength (1650 MPa and $1800 \mathrm{MPa}$ ) and higher contamination from long milling time and increased amount of PCA. The sample from 10 hours milled powder has the best mechanical performance since it exhibits a combination of high yield strength of $\sim 1.2 \mathrm{GPa}$ and good ductility with a compressive strain of $60 \%$ before failure (when failure occurs, the ultimate stress is as high as $1.85 \mathrm{GPa}$ ). This high-performance nanostructured pure Ti has higher 
strength and better ductility than common Ti-6Al-4V alloys and most ufg/nc Ti processed by SPD techniques.

Figure 2 demonstrates the uniaxial stress strain curves of ufg/nc $\mathrm{Ti}$ at quasi-static strain rates reported in the literature in comparison with this study (note that solid lines represent compressive experiments results and dashed lines represent tensile experiments results). The measured responses in this study are clearly superior in terms of strength and ductility.

\subsubsection{Strain rate effect}

Figure 3(a), (b), (c) show the uniaxial compressive stress-strain responses of un-milled, 5 hours and 10 hours milled bulk Ti at RT and the quasi-static strain rates of $10^{-4}, 10^{-2}, 1 \mathrm{~s}^{-1}$. The responses of strain rate of $10^{-4}, 10^{-2} \mathrm{~s}^{-1}$ indicate a pronounced positive strain rate sensitivity of flow stress for ufg/nc Ti.

At a strain rate of $1 s^{-1}$, after certain amount of strain, the flow stresses of all three materials begin to drop. The observed softening at a strain rate of $1 s^{-1}$ is believed to be the result of temperature increase during the deformation. To remove (at least reduce) the effect of temperature increase, a $1 s^{-1}$ compression experiment was performed by loading the sample with intervals of about $5 \%$ strain, and between each interval the loading was paused for 30 min so the increased temperature can cool to RT. A rough isothermal stress-strain curve was obtained by connecting the elastic part of the first loading with the highest flow stress of each reloading (see Figure. 4). As demonstrated by the isothermal curve in Figure 4, when the temperature increase was removed/reduced, the ufg/nc Ti at $1 s^{-1}$ showed hardening behavior instead of softening. This thermal softening behavior at an intermediate strain rate of $1 s^{-1}$ was also observed in ufg Ti processed by ECAP (Meredith and Khan, 2012). 
Since the stresses drop due to thermal softening at the strain rate of $1 s^{-1}$, strain rate sensitivity parameter $\mathrm{m}$ was only calculated using the $10^{-4}$ and $10^{-2} \mathrm{~s}^{-1}$ curves.

The strain rate sensitivity (SRS) was quantified using the equation:

$$
\mathrm{m}=\frac{\log \left(\sigma_{1} / \sigma_{2}\right)}{\log \left(\dot{\varepsilon}_{1} / \dot{\varepsilon}_{2}\right)}
$$

where $\mathrm{m}$ is the strain rate sensitivity parameter, $\sigma_{1}$ and $\sigma_{2}$ are the flow stress values at the same strain from experiments performed with strain rates $\dot{\varepsilon}_{1}$ and $\dot{\varepsilon}_{2}$, respectively. For each material (un-milled, 5 and 10 hours milled), separate $\mathrm{m}$ values were calculated at different true strain values (every $5 \%$ of strain) and then an average $m$ was obtained.

The values of the measured average strain rate sensitivity $\mathrm{m}$ of un-milled, 5 and 10 hours milled Ti are 0.022, 0.018 and 0.0166, respectively. Similar m values have been observed of ufg/nc Ti obtained by cryomilling followed by hot quasi-isostatic forging or spark plasma sintering (Yin et al., 2013). In this study, a decrease of $\mathrm{m}$ with increasing milling time was observed. Further study is needed for the microstructure such as grain size distribution and the underlying deformation mechanisms.

\subsubsection{Temperature effect}

Figure 5 shows the uniaxial compressive stress-strain responses of 10 hours milled bulk $\mathrm{ufg} / \mathrm{nc} \mathrm{Ti}$ at different temperatures at a strain rate of $10^{-2} \mathrm{~s}^{-1}$. It shows the usual thermal softening as the temperature increases.

\subsubsection{Dynamic experiments}

The dynamic compressive response of the 10 hours milled $\mathrm{Ti}$ at a strain rate of $1340 \mathrm{~s}^{-1}$ is shown in Figure 3(c) along with the responses at strain rates of $10^{-4}, 10^{-2}$, and $1 \mathrm{~s}^{-1}$. The response at the first few percent of strain was not included because of large experimental errors. The flow 
stresses at the dynamic strain rate were around $1700 \mathrm{MPa}$ which were much higher than those of quasi-static strain rates. Thermal softening due to the rise of specimen temperature was observed. The sample failed due to the formation of the macroscopic shear band at a strain of about of $17 \%$, which was much smaller than the failing strains at quasi-static strain rates. Meredith and Khan (2012) also observed macroscopic shear band failures in the dynamic compressive of ufg $\mathrm{Ti}$ processed by ECAP.

\subsection{Texture evolution under compression}

Figure 6(a) is the measured texture of an as-prepared sample (from 5 hours milled powder). Because of the axial symmetry of the synthesis procedures (the powder consolidation and the heat treatment), an axial symmetry of the texture about the compaction direction was expected for the as-prepared samples. An almost axially symmetrical texture about the compaction direction can be observed in figure 6(a). Note that the range of MRD (multiples of a random density) for the as-prepared sample pole figures is small, so it is a weak axially symmetrical texture. The starting material (un-milled, un-compacted powder) should have a random texture i.e. no texture. And the final weak axially symmetrical texture was due to the sequence of compaction and heat treatment. Only weak anisotropy was observed as a result of the weak texture.

Figures 6(b) and 6(c) are the textures of samples (from 10 hours milled powder) that were compressively deformed to a strain of $30 \%$ and $50 \%$, respectively, at room temperature and a quasi-static strain rate. It is clear that stronger texture patterns have developed. The texture of the sample deformed to $50 \%$ strain is similar to that of sample deformed to $30 \%$ strain only with a stronger intensity due to a larger imposed strain. 
From the (0002) basal pole figure of the deformed samples (Figures 6(b) and 6(c)), it is clear that the basal pole moves toward the compaction direction instead of toward the compression direction. When under compression, it is well known that the basal pole would move toward the compression axis if basal slip and tensile twinning were the dominant deformation mechanisms (Agnew et al., 2001). In Figures 6(b) and 6(c), the fact that the (0002) basal pole moves toward the compaction direction (instead of toward the compression direction) during compressive loading indicates that the activities of basal slip and tensile twinning are significantly prohibited. Although nc FCC metals deform by twinning more readily than their coarse-grained counterparts, twinning is usually absent in nc HCP metals and alloys (Zhu et al., 2012). Now the possible dominant mechanisms that are responsible for the non-basal texture are prismatic slip, pyramidal $\langle a\rangle$ and pyramidal $\langle c+a\rangle$ slip (based on the known major deformation modes of HCP). Simulations using polycrystal plasticity modeling codes (such as VPSC code by LANL) are needed for a further quantitative analysis.

\section{Macroscopic constitutive model}

The Khan-Huang-Liang model (Khan and Liang, 1999) and its variations (Khan et al., 2000; Khan et al., 2004; Khan et al., 2006) are macroscopic phenomenological viscoplastic constitutive models that have been successfully applied to simulate the responses of various metallic materials for wide ranges of grain sizes, strain rates, and temperatures. The new grain size and temperature dependent Khan-Liang-Farrokh (KLF) model was developed by Farrokh and Khan (2009) based on the early works on the modeling (Khan et al., 2000; Khan et al., 2004; Khan et al., 2006) and on the experimental observations on post-yield mechanical properties of ufg and 
nc materials (Khan et al., 2008a, 2008b). In this research, the following Khan-Liang-Farrokh (KLF) constitutive model is used to simulate the responses of $\mathrm{ufg} / \mathrm{nc} \mathrm{Ti}$ :

$$
\sigma=\left[\left(a+\frac{k}{\sqrt{d}}\right)+B\left(\frac{d}{d_{0}}\right)^{n_{2}}\left(\left(1-\frac{\ln \dot{\varepsilon}}{\ln D_{0}^{p}}\right)\left(\frac{T_{m}}{T}\right)\right)^{n_{1}}\left(\varepsilon_{p}\right)^{n_{0}}\right]\left(\frac{\dot{\varepsilon}}{\dot{\varepsilon}^{*}}\right)^{c}\left(\frac{T_{m}-T}{T_{m}-T_{r e f}}\right)^{m_{T}}
$$

where $\varepsilon_{p}, \dot{\varepsilon}$ and $\sigma$ are the plastic strain, the current strain rate and the flow stress, respectively. $T, T_{m}$ and $T_{\text {ref }}$ are the current, melting and reference temperatures. $D_{0}^{p}=10^{6} s^{-1}$ is the arbitrary chosen upper bound strain rate. $\dot{\varepsilon}^{*}=1 s^{-1}$ is the reference strain rate at which some material constants are determined. $d$ and $d_{0}$ are the average grain size of the material being studied and its corresponding coarse-grained counterpart $\left(d_{0}=50 \mu \mathrm{m}\right)$, respectively. The material constants of the model which need to be determined are: $a, k, B, n_{0}, n_{1}, n_{2}$, c and $m_{T}$.

The initial values of those material constants can be determined by following the systematic procedures outlined by Farrokh and Khan (2009). Then, by using a non-linear least squares regression based optimization program, the initial values are adjusted to obtain the final optimized material constants. The optimized material constants are listed in Table 2.

By using the material constants that are listed in Table 2, the KLF constitutive model is used to correlate the thermo-mechanical responses of ufg/nc Ti of different grain sizes and at various strain rates and temperatures. Fig 7 shows numerical results of the KLF model along with the experimental data for $\mathrm{ufg} / \mathrm{nc} \mathrm{Ti}$ with different grain sizes (different milling time), determined at the strain rate of $10^{-4} s^{-1}$ and at room temperature. In most cases, the calculated curves are in good agreement with the experimental results except for the grain size of $43 \mathrm{~nm}$, which was obtained by 20 hours of milling. The discrepancy between experimental and model correlation of 20 hours milled sample is possibly due to the high impurity level as a result of long milling time and large amount of PCA. 
As evidenced from the experimental results, there is thermal softening at an intermediate strain rate of $1 s^{-1}$. During the deformation at strain rates of $1 s^{-1}$, a significant part of the heat generated by the plastic work is entrapped within the specimen, causing a temperature increase. The temperature rise in the specimen can be estimated using the following equation:

$$
\Delta \mathrm{T}=\frac{\beta}{\rho C_{\rho}} \int_{0}^{\varepsilon^{p *}}\left(\sigma^{p}\right) d \varepsilon^{p}
$$

where $\rho$ and $C_{\rho}$ are the mass density and the specific heat at constant pressure of the material, repectively. For titanium, $\rho$ and $C_{\rho}$ are $4500 \mathrm{~kg} / \mathrm{m}^{3}$ and $540 \mathrm{~J} / \mathrm{kgK}$, respectively. $\beta$ is the fraction of plastic work that is converted to heat. Thermal softening is mostly observed at high dynamic strain rates, and the fraction $\beta$ is usually taken to be 0.9 or 1.0 . In this study, we use the KLF model to simulate the response of ufg/nc Ti at an intermediate strain rate of $1 s^{-1}$ and dynamic strain rate considering the thermal softening due to temperature rise. $\beta=0.9$ was used in the simulations. Figure 8(a), (b), (c) illustrates the experimental data along with the model correlations for the samples made from un-milled, 5 and 10 hours milled powders at different strain rates. The simulation responses at $1 s^{-1}$ and dynamic strain rates are adiabatic, i.e., temperature rise is taken into account. It is clear that the KLF model is able to simulate the strain rate effect of ufg/nc Ti very well.

Figure 9 shows the experimental data along with the model correlations for the 10 hours milled bulk Ti at different temperature and at a strain rate of $10^{-2} \mathrm{~s}^{-1}$. Except for the initial part of the highest temperature curve, the model is able to successfully capture the response of ufg/nc $\mathrm{Ti}$ at different temperatures. 


\section{Conclusions}

For the first time, room temperature mechanical milling and conventional hot compaction were used to successfully produce fully dense bulk ufg/nc Ti samples. High performance nanostructured pure Ti samples were obtained, among which the 10 hours milled sample had higher strength and better ductility than common Ti-6Al-4V alloys and Ti processed by SPD techniques.

Experimental data on compressive responses of ufg/nc Ti with different grain sizes, at a wide range of strain rates and temperatures, and to very large values of strain were reported. Thermal softening at an intermediate strain rate of $1 s^{-1}$ was observed. The values of measured average strain rate sensitivity $\mathrm{m}$ of un-milled, 5 and 10 hours milled Ti were calculated to be $0.022,0.018$ and 0.0166, respectively. A decrease of $\mathrm{m}$ with decreasing grain size was observed.

The textures of the as-prepared and compressively deformed samples were measured by SXRD technique and were qualitatively analyzed. The as-prepared samples showed a weak axially symmetrical texture about the powder compaction direction. Strong texture patterns developed after the samples were compressively deformed in the direction perpendicular to the powder compaction. The fact that the (0002) basal pole does not move toward the compression direction indicated that the activities of basal slip and tensile twinning were significantly prohibited in the ufg/nc Ti.

A grain size and temperature dependent visco-plastic constitutive model was used to simulate the post yield behavior of ufg/nc Ti. A good correlation between the model and the experimental data was found. 


\section{Acknowledgement}

JL gratefully acknowledges the China Scholarship Council (SCS, China) for the financial support. Use of the Advanced Photon Source, an Office of Science User Facility operated for the U.S. Department of Energy (DOE) Office of Science by Argonne National Laboratory, was supported by the U.S. DOE under Contract No. DE-AC02-06CH11357. 


\section{References}

Agnew, S.R., Yoo, M.H., and Tomé, C.N., 2001, Application of texture simulation to understanding mechanical behavior of $\mathrm{Mg}$ and solid solution alloys containing Li or Y. Acta Materialia 49, no. 20, 4277-89.

Barai, P., Weng, G.J., 2009. Mechanics of very fine-grained nanocrystalline materials with contributions from grain interior, GB zone, and grain-boundary sliding. International Journal of Plasticity 25, 2410-2434. doi:10.1016/j.ijplas.2009.04.001

Dabhade, V., 2001. Synthesis of nanosized titanium powder by high energy milling. Applied Surface Science 182, 390-393.

Dabhade, V.V., Panigrahi, B.B., Godkhindi, M.M., Rama Mohan, T.R., Ramakrishnan, P., 2006. Dilatometry of attrition milled nanocrystalline titanium powders. Materials Research Bulletin 41, 2111-2122.

Edalati, K., Matsubara, E., Horita, Z., 2009. Processing pure Ti by high-pressure torsion in wide ranges of pressures and strain. Metall and Mat Trans A 40, 2079-2086.

Ertorer, O., Topping, T., Li, Y., Moss, W., Lavernia, E.J., 2009. Enhanced tensile strength and high ductility in cryomilled commercially pure titanium. Scripta Materialia 60, 586-589. doi:10.1016/j.scriptamat.2008.12.017

Ertorer, O., Topping, T., Li, Y., Moss, W., Lavernia, E.J., 2010. Nanostructured Ti consolidated via spark plasma sintering. Metallurgical and Materials Transactions A 42, 964-973.

Ertorer, O., Zúñiga, A., Topping, T., Moss, W., Lavernia, E.J., 2008. Mechanical behavior of cryomilled CP-Ti consolidated via quasi-isostatic forging. Metallurgical and Materials Transactions A 40, 91-103.

Farrokh, B, and AS Khan, 2009. Grain size, strain rate, and temperature dependence of flow stress in ultra-fine grained and nanocrystalline $\mathrm{Cu}$ and $\mathrm{Al}$ : Synthesis, Experiment, and Constitutive Modeling. International Journal of Plasticity 25, no. 5, 715-732.

Feng, H., Fang, Q.H., Zhang, L.C., Liu, Y.W., 2013. Special rotational deformation and grain size effect on fracture toughness of nanocrystalline materials. International Journal of Plasticity 42, 50-64. doi:10.1016/j.ijplas.2012.09.015

Garbacz, H., Lewandowska, M., Pachla, W., Kurzydłowski, K.J., 2006. Structural and mechanical properties of nanocrystalline titanium and 316LVM steel processed by hydrostatic extrusion. Journal of Microscopy 223, 272-274.

Gleiter, H., 1989. Nanocrystalline materials. Progress in Materials Science 33, 223-315. 
Hyun, C.Y., Lee, J.H., Kim, H.K., 2010. Microstructures and mechanical properties of ultrafine grained pure Ti produced by severe plastic deformation. Research on Chemical Intermediates 36, 629-638.

Ivanisenko, Y., Tabachnikova, E.D., Psaruk, I.A., Smirnov, S.N., Kilmametov, A., Kobler, A., Kübel, C., Kurmanaeva, L., Csach, K., Mishkuf, Y., Scherer, T., Semerenko, Y.A., Hahn, H., 2014. Variation of the deformation mechanisms in a nanocrystalline $\mathrm{Pd}-10 \mathrm{at} \% \mathrm{Au}$ alloy at room and cryogenic temperatures. International Journal of Plasticity 60, 40-57. doi:10.1016/j.ijplas.2014.04.011

Jia, D., Wang, Y.M., Ramesh, K.T., Ma, E., Zhu, Y.T., Valiev, R.Z., 2001. Deformation behavior and plastic instabilities of ultrafine-grained titanium. Applied Physical Letter 79, 611.

Khan, A., Farrokh, B., Takacs, L., 2008a. Compressive properties of $\mathrm{Cu}$ with different grain sizes: sub-micron to nanometer realm. Journal of Materials Science 43, 3305-3313.

Khan, A., Farrokh, B., Takacs, L., 2008b. Effect of grain refinement on mechanical properties of ball-milled bulk aluminum. Materials Science and Engineering A. Structural Materials Properties 489, 77-84.

Khan, AS, R Kazmi, and B Farrokh., 2007. Multiaxial and non-proportional loading responses, anisotropy and modeling of Ti-6Al-4V titanium alloy over wide ranges of strain rates and temperatures. International Journal of Plasticity 23, no. 6, 931-950.

Khan, A.S., Liang, R., 1999. Behaviors of three bcc metal over a wide range of strain rates and temperatures: experiments and modeling. International Journal of Plasticity 15 (10), 1089-1109.

Khan, A. S, Y. S Suh, X. Chen, L. Takacs, and H. Zhang, 2006. Nanocrystalline aluminum and iron: mechanical behavior at quasi-static and high strain rates, and constitutive modeling. International Journal of Plasticity 22, no. 2, 195-209.

Khan, AS, YS Suh, and R Kazmi, 2004. Quasi-static and dynamic loading responses and constitutive modeling of titanium alloys. International Journal of Plasticity 20, no. 12, 22332248.

Khan, A., Zhang, H., Takacs, L., 2000. Mechanical response and modeling of fully compacted nanocrystalline iron and copper. International Journal of Plasticity 16, 1459-1476.

Ko, Y.G., Shin, D.H., Park, K.-T., Lee, C.S., 2006. An analysis of the strain hardening behavior of ultra-fine grain pure titanium. Script Materialia 54, 1785-1789.

Korshunov, A., Kravchenko, T., Polyakov, L., Smolyakov, A., Vedernikova, I., Morozov, A., 2008. Effects of the number of equal-channel angular pressing passes on the anisotropy of ultrafine titanium. Materials Science and Engineering: A 493, 160-163.

Kumar, S., Haque, M.A., Gao, H., 2013. Transformation induced toughening and flaw tolerance in pure nanocrystalline aluminum. International Journal of Plasticity 44, 121-128. doi:10.1016/j.ijplas.2012.12.005 

Valiev, R.Z., 2006. Microstructure and properties of Ti rods produced by multi-step SPD. Materials Science Forum 503-504, 763-768.

Meredith, C.S., Khan, A.S, 2012. Texture evolution and anisotropy in the thermo-mechanical response of ufg $\mathrm{Ti}$ processed via equal channel angular pressing. International Journal of Plasticity 30-31, 202-17.

Meyers, M., Mishra, A., Benson, D., 2006. Mechanical properties of nanocrystalline materials. Progress in Materials Science 51, 427-556.

Moskalenko, V.A., Smirnov, A.R., Moskalenko, A.V., 2009. Cryomechanically obtained nanocrystalline titanium: microstructure and mechanical properties. Low Temperature Physics. 35,905 .

Okamoto, N.L., Kashioka, D., Hirato, T., Inui, H., 2014. Specimen- and grain-size dependence of compression deformation behavior in nanocrystalline copper. International Journal of Plasticity 56, 173-183. doi:10.1016/j.ijplas.2013.12.003

Pachla, W., Kulczyk, M., Susryszkowska, M., Mazur, A., Kurzydlowski, K., 2008. Nanocrystalline titanium produced by hydrostatic extrusion. Journal of Materials Processing Technology 205, 173-182.

Panigrahi, B.B., Godkhindi, M.M., 2006. Grain growth in ultrafine titanium powders during sintering. Journal of Nanoparticle Research 8, 627-633.

Popov, A., 1997. Structural and mechanical properties of nanocrystalleve titanium processed by severe plastic deformation. Scripta Materialia 37, 1089-1094.

Sadikova, G., Latysh, V., Semenova, I., Valiev, R., 2005. Effect of severe plastic deformation and thermomechanical treatment on the structure and properties of titanium. Metal Science and Heat Treatment 47, 512-515.

Salimgareeva, G.H., Semenova, I.P., Latysh, V.V., Kandarov, I.V., Valiev, R.Z., 2006. Combined SPD techniques to fabricate nanostructured Ti rods for medical applications. Solid State Phenomena 114, 183-188.

Semenova, I.P., Korshunov, A.I., Salimgareeva, G.K., Latysh, V.V., Yakushina, E.B., Valiev, R.Z., 2008. Mechanical behavior of ultrafine-grained titanium rods obtained using severe plastic deformation. Physics of Metals and Metallography. 106, 211-218.

Sergueeva, A., Stolyarov, V., Valiev, R.., Mukherjee, A., 2001. Advanced mechanical properties of pure titanium with ultrafine grained structure. Scripta Materialia 45, 747-752.

Shpě̌zman, V.V., Nikolaev, V.I., Peschanskaya, N.N., Romanov, A.E., Smirnov, B.I., Aleksandrov, I.A., Enikeev, N.A., Kazykhanov, V.U., Nazarov, A.A., 2007. Low-temperature plasticity in nanocrystalline titanium and copper. Physics of the Solid State 49, 678-683. 

and properties of pure Ti processed by warm ECAP and cold rolling. Materials Science and Engineering: A 343, 43-50.

Stolyarov, Vladimir V., Zhu, Y.T., Lowe, T.C., Valiev, R.Z., 2001. Microstructures and properties of ultrafine-grained pure titanium processed by equal-channel angular pressing and cold deformation. Journal of Nanoscience and Nanotechnology 1, 237-242.

Sun, F., Rojas, P., Zúñiga, A., Lavernia, E.J., 2006a. Nanostructure in a Ti alloy processed using a cryomilling technique. Materials Science and Engineering: A 430, 90-97.

Sun, F., Zúñiga, A., Rojas, P., Lavernia, E.J., 2006b. Thermal stability and recrystallization of nanocrystalline Ti produced by cryogenic milling. Metallurgical and Materials Transactions A 37, 2069-2078.

Suryanarayana, C., 2001. Mechanical alloying and milling. Progress in Materials Science 46, 1184.

Tabachnikova, E., Bengus, V., Podolskiy, A., Smirnov, S., Natsik, V., Csach, K., Miskuf, J., Gunderov, D., Valiev, R., 2005. Low temperature features of mechanical properties and failure of different commercial purity nanostructured titanium processed by ECA pressing. Reviews on Advanced Materials Science 10, 229-234.

Terada, D., Inoue, S., Tsuji, N., 2007. Microstructure and mechanical properties of commercial purity titanium severely deformed by ARB process. Journal of Materials Science 42, 1673-1681.

Topolski, K., Garbacz, H., Pachla, W., Kurzydlowski, K.J., 2010. Bulk nanostructured titanium fabricated by hydrostatic extrusion. physica status solidi (c) 7, 1391-1394.

Valiev, R.Z., Semenova, I.P., Jakushina, E., Latysh, V.V., Rack, H.J., Lowe, T.C., Petruželka, J., Dluhoš, L., Hrušák, D., Sochová, J., 2008. Nanostructured SPD processed titanium for medical implants. Materials Science Forum 584-586, 49-54.

Wang, K.Y., Shen, T.D., Quan, M.X., Wei, W.D., 1993. Hall-Petch relationship in nanocrystalline titanium produced by ball-milling. Journal of Materials Science Letters 12, 1818-1820.

Wenk, H.R., Lutterotti, L., Vogel, S., 2003. Texture analysis with the new HIPPO TOF diffractometer. Nuclear Instruments and Methods in Physics Research Section A: Accelerators, Spectrometers, Detectors and Associated Equipment 515, 575-588. doi:10.1016/j.nima.2003.05.001

Zhernakov, V.., Latysh, V.., Stolyarov, V.., Zharikov, A.., Valiev, R.., 2001. The developing of nanostructured SPD Ti for structural use. Scripta Materialia 44, 1771-1774.

Zhu, Y.T., Kolobov, Y.R., Grabovetskaya, G.P., Stolyarov, V.V., Girsova, N.V., Valiev, R.Z., 2003. Microstructures and mechanical properties of ultrafine-grained Ti foil processed by equalchannel angular pressing and cold rolling. Journal of Materials Research 18, 1011-1016. 
Table 1 . The conditions of the consolidation process for mechanically milled Ti powder.

\begin{tabular}{|l|l|l|l|l|l|l|}
\hline \multicolumn{2}{|l|}{ Compaction } & \multicolumn{2}{l|}{ Heat Treatment } \\
\hline Cold (296K) & \multicolumn{2}{l|}{ Warm } & \multicolumn{2}{l|}{} \\
\hline Pressure (GPa) & Time(min) & Pressure (GPa) & Time (min) & Temp (K) & Temp (K) & Time (hr) \\
\hline 1.4 & 5 & 1 & 60 & 873 & 1073 & 8 \\
\hline
\end{tabular}

Table 2. The optimized material constants for the KLF model

\begin{tabular}{|l|l|l|l|l|l|l|l|}
\hline $\mathrm{a}(\mathrm{MPa})$ & $\mathrm{k}\left(\mathrm{MPa} / \mathrm{nm}^{-1 / 2}\right)$ & $\mathrm{B}(\mathrm{MPa})$ & $\mathrm{n}_{2}$ & $\mathrm{n}_{1}$ & $\mathrm{n}_{0}$ & $\mathrm{c}$ & $\mathrm{m}_{\mathrm{T}}$ \\
\hline-939 & 18894 & 5331 & 0.136 & -0.337 & 0.564 & 0.0142 & 5.54 \\
\hline
\end{tabular}




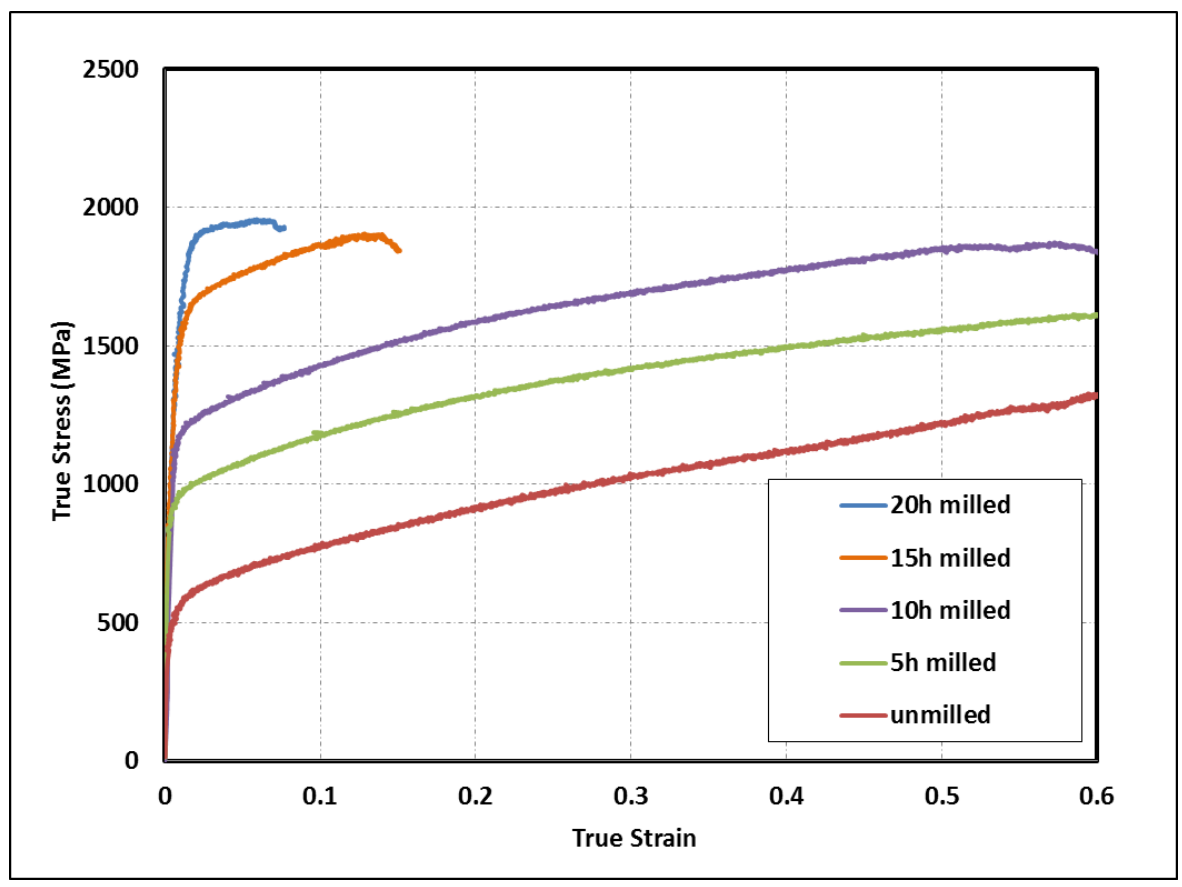

Figure 1. The effect of milling time on the compressive uniaxial stress-strain response of mechanically milled Ti at RT and a strain rate of $10^{-4} \mathrm{~s}^{-1}$. 


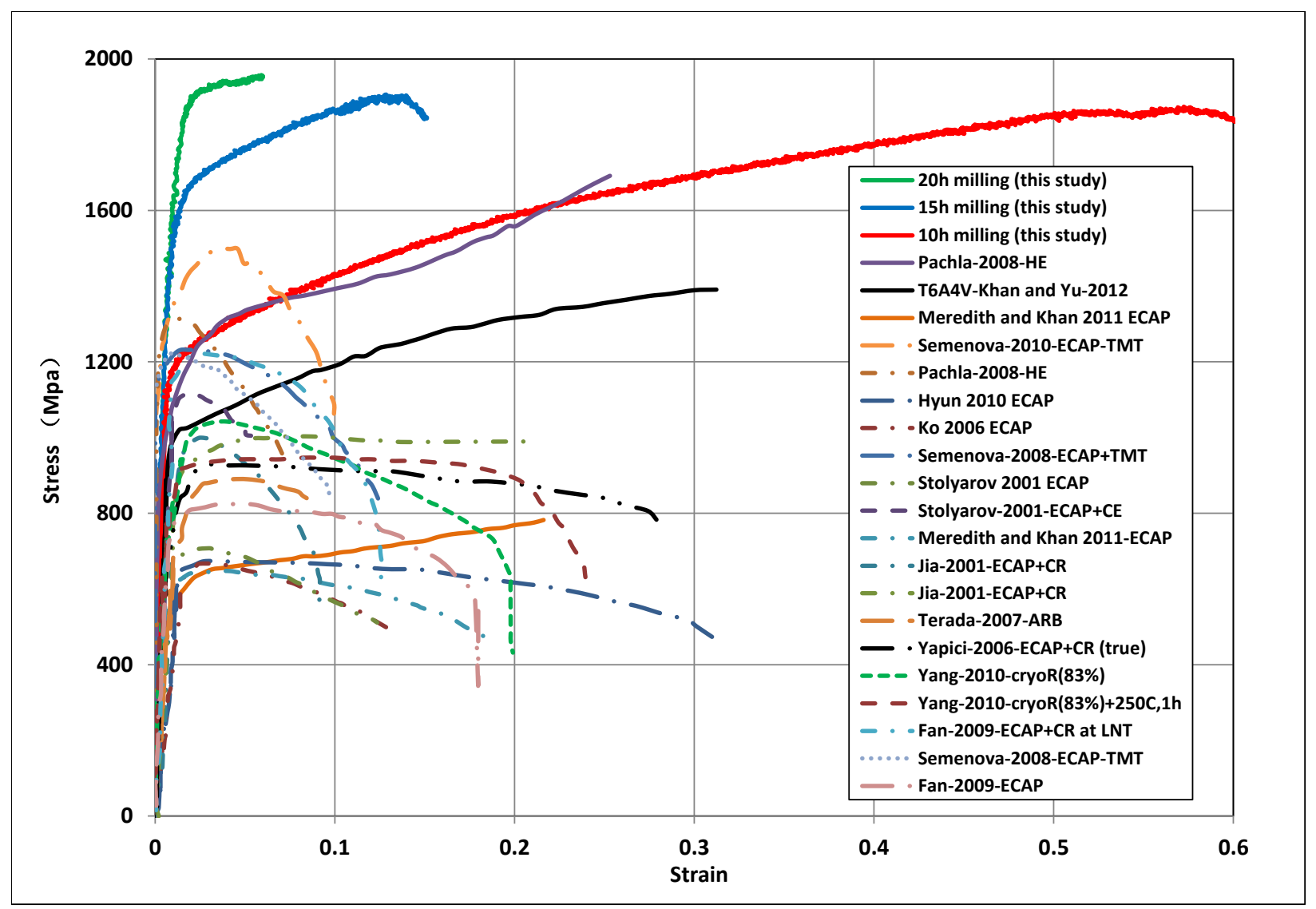

Figure 2. Results of uniaxial compression/tensile tests of ufg and nc Ti at quasi-static strain rates reported in the literature in comparison with the responses of ufg/nc Ti of this study (Solid lines represent compressive tests results and dashed lines represent tensile tests results). 


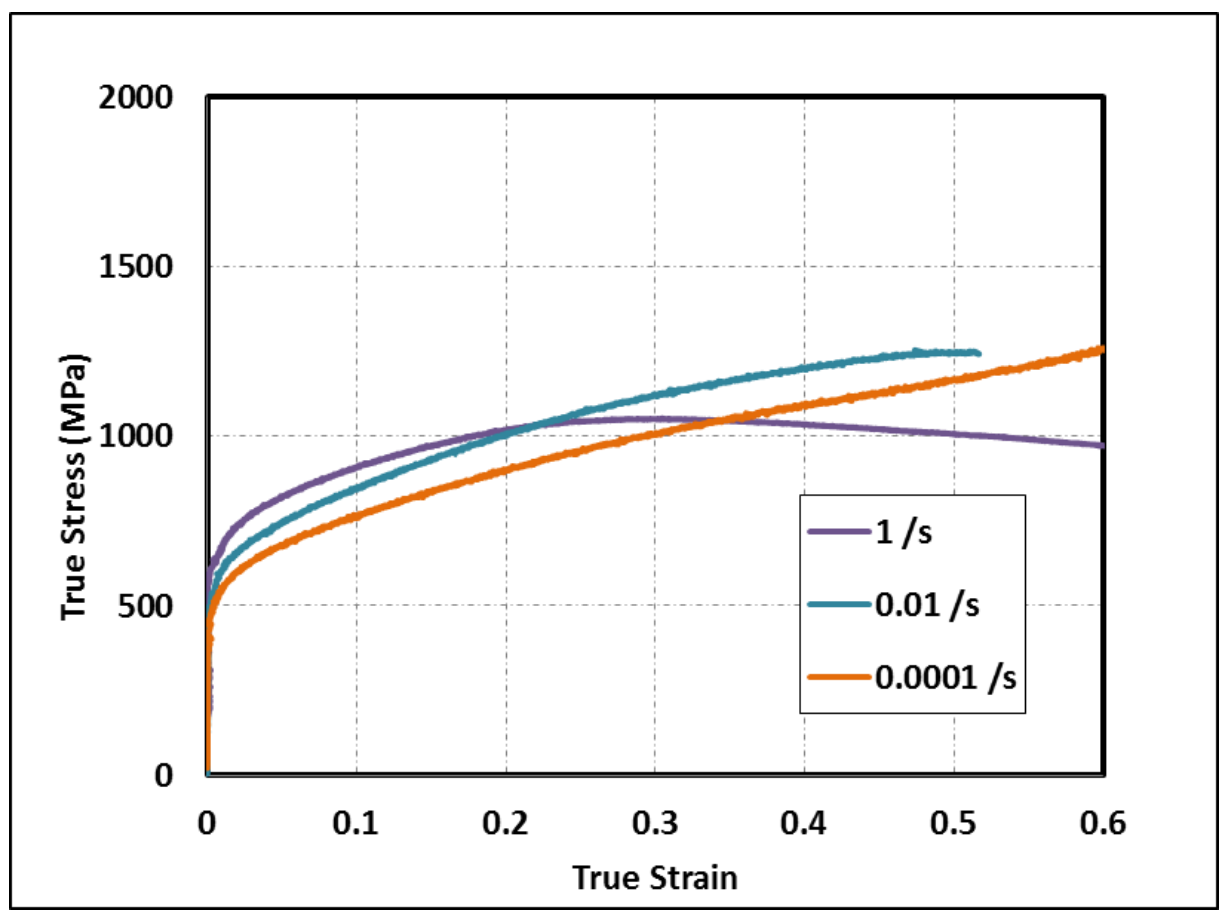

(a)

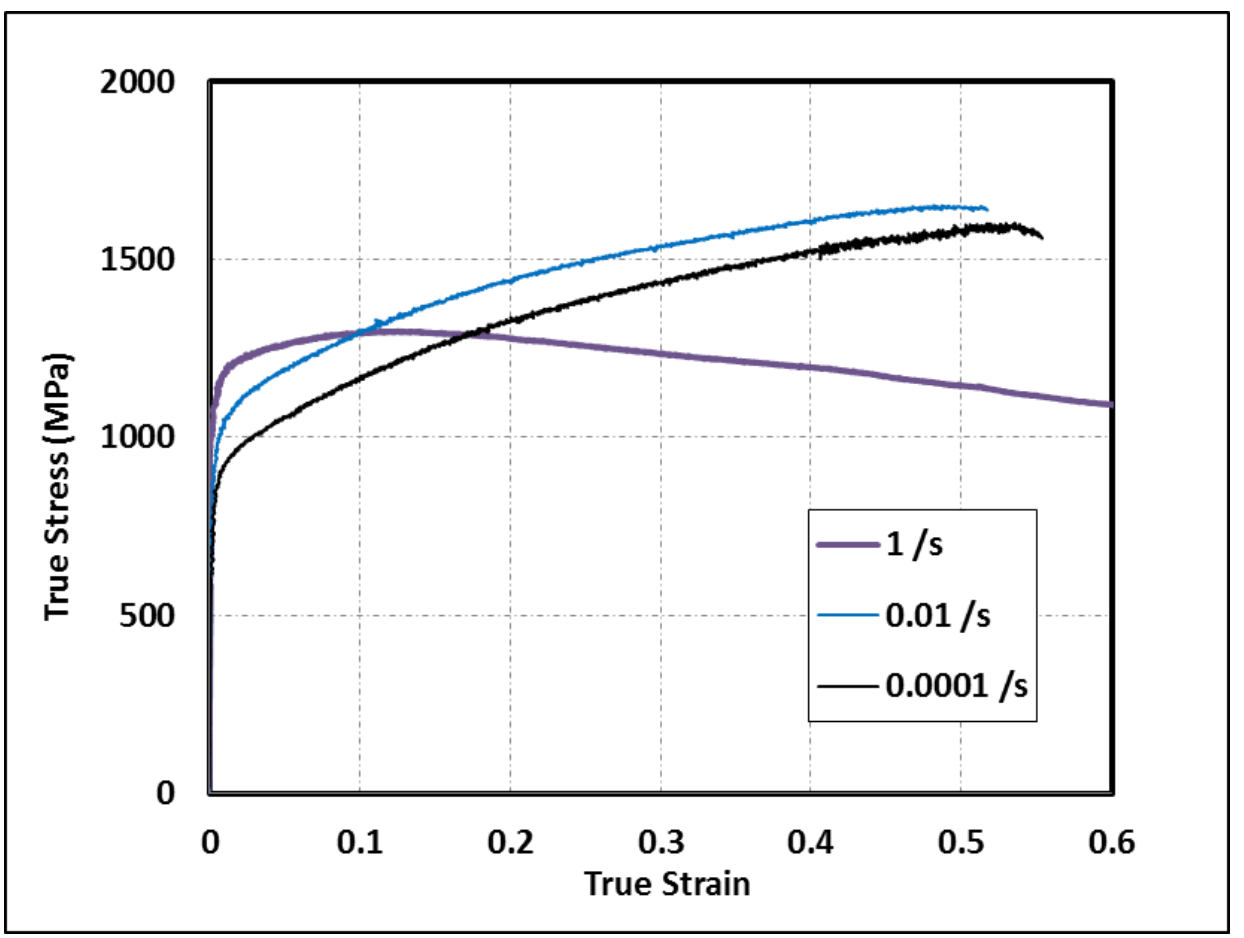

(b) 


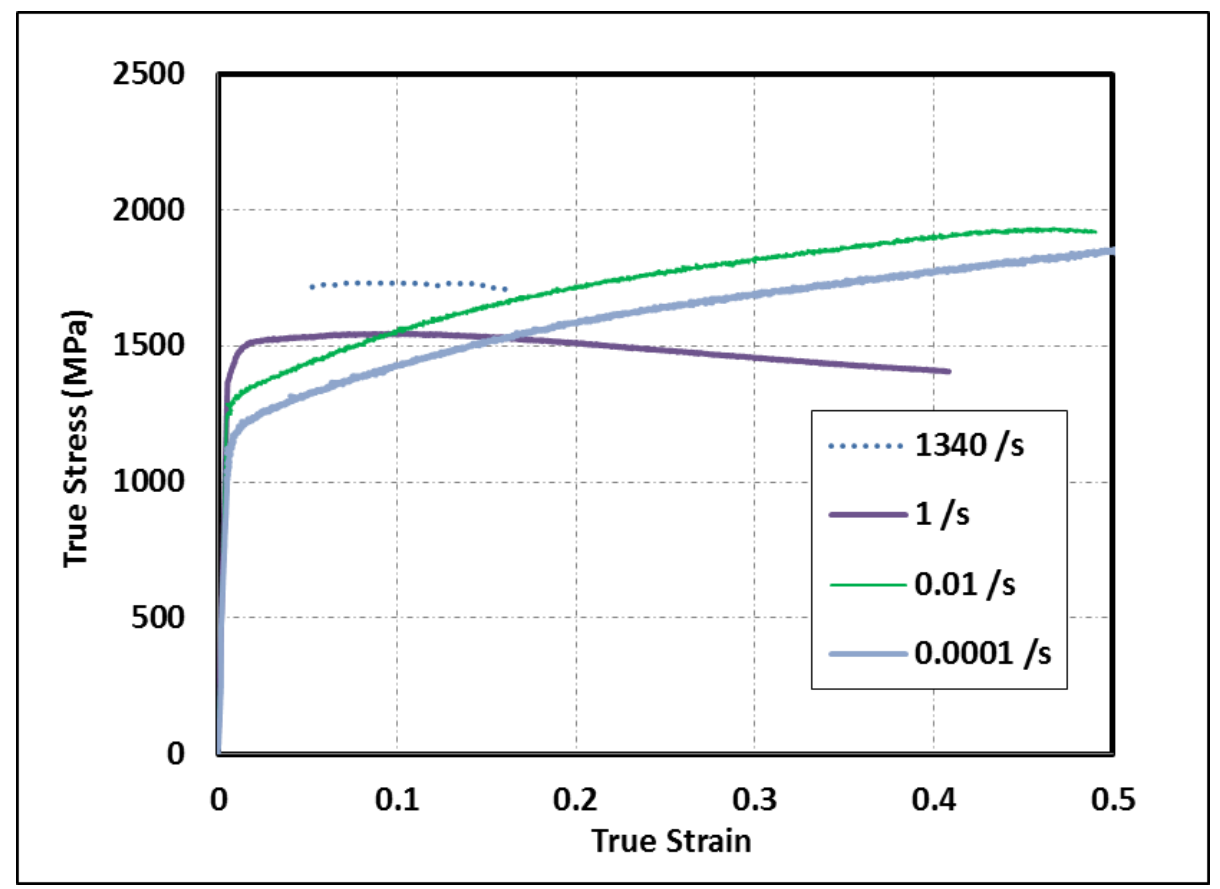

(c)

Figure 3. The compressive stress-strain response at RT and different strain rates of ufg/nc Ti that made from (a) un-milled powder, (b) $5 \mathrm{~h}$ milled powder, (c) $10 \mathrm{~h}$ milled powder. 


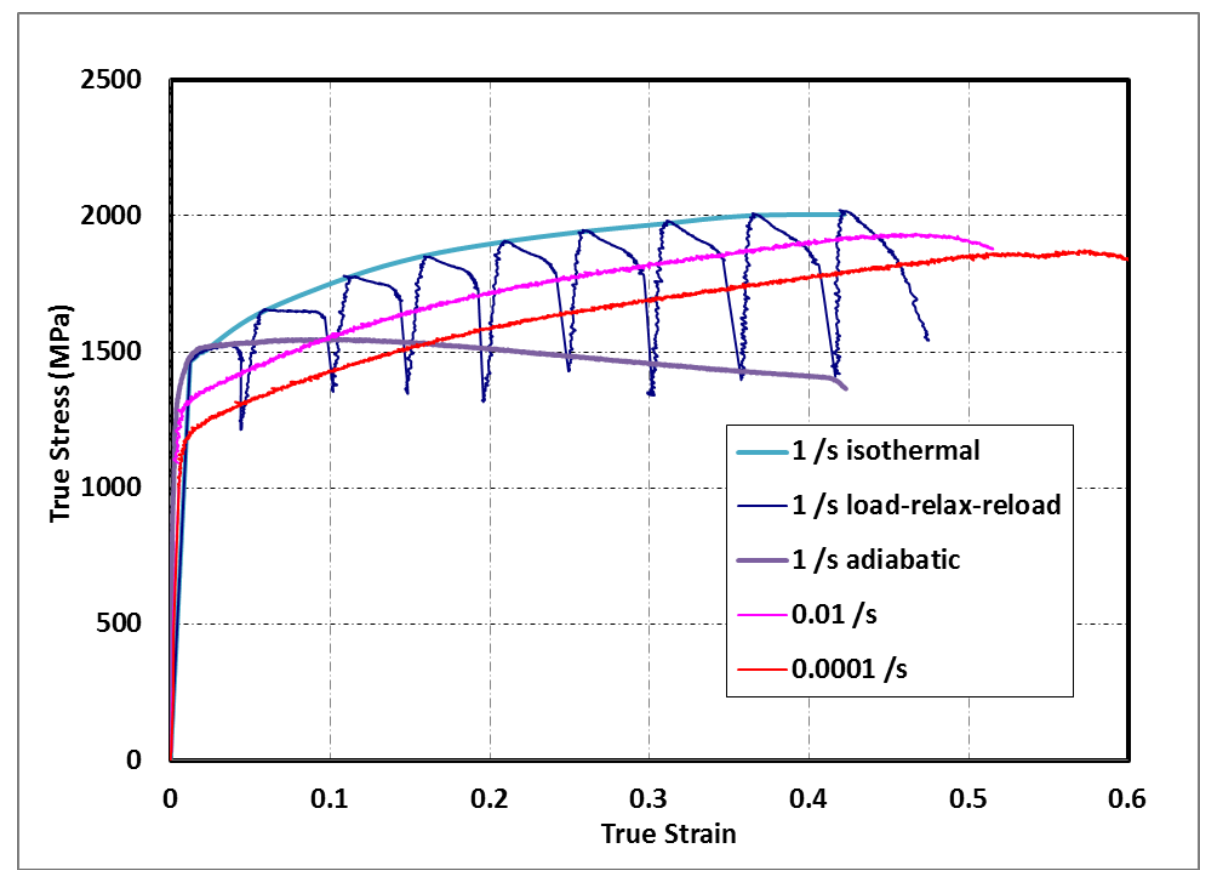

Figure 4. The compressive stress-strain response of $10 \mathrm{~h}$ milled $\mathrm{Ti}$ with isothermal and adiabatic curves at strain rate $1 \mathrm{~s}^{-1}$. 


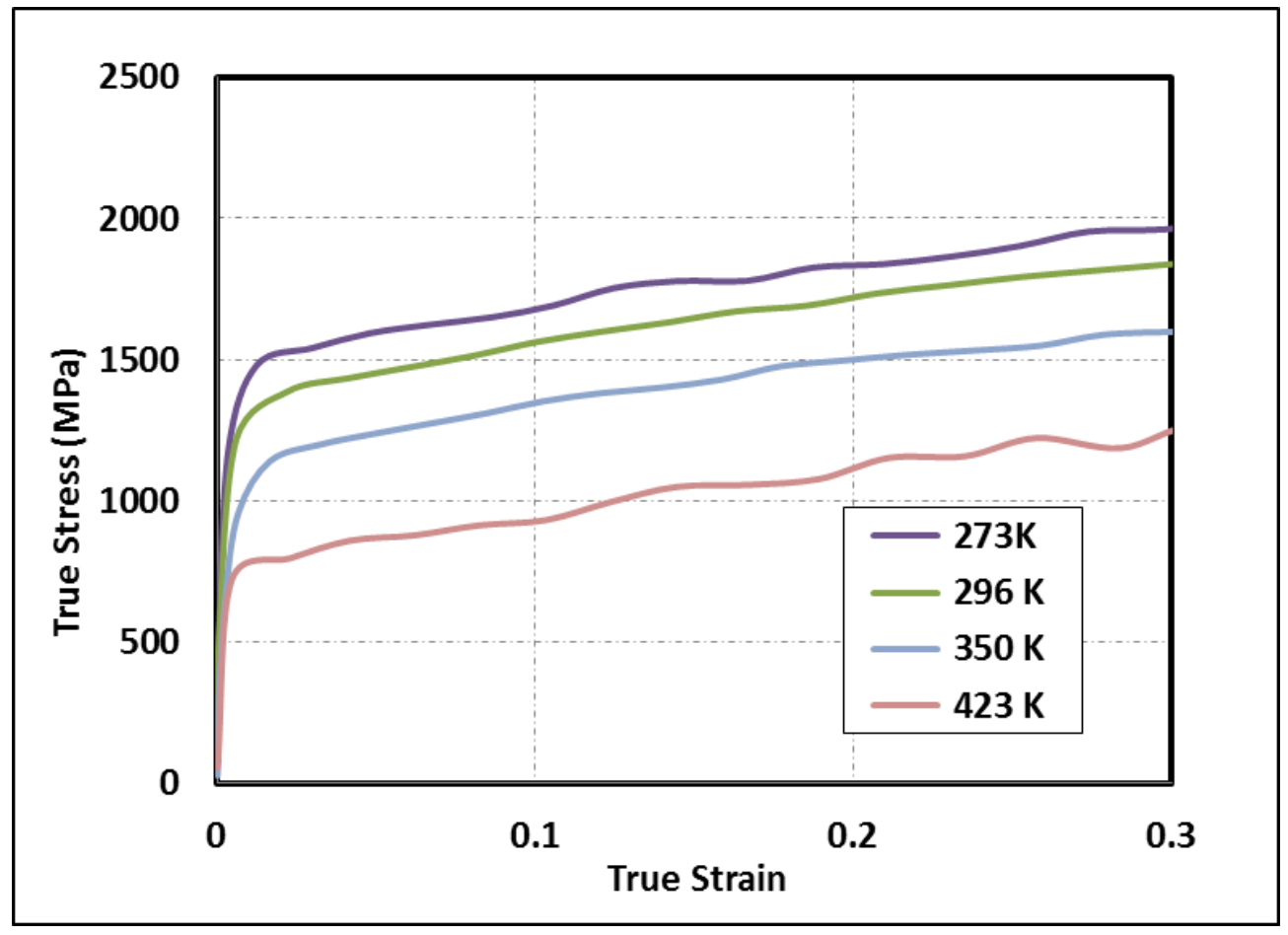

Figure 5. The compressive stress-strain response of $10 \mathrm{~h}$ milled $\mathrm{Ti}$ at different temperatures at a strain rate of $10^{-2} s^{-1}$. 

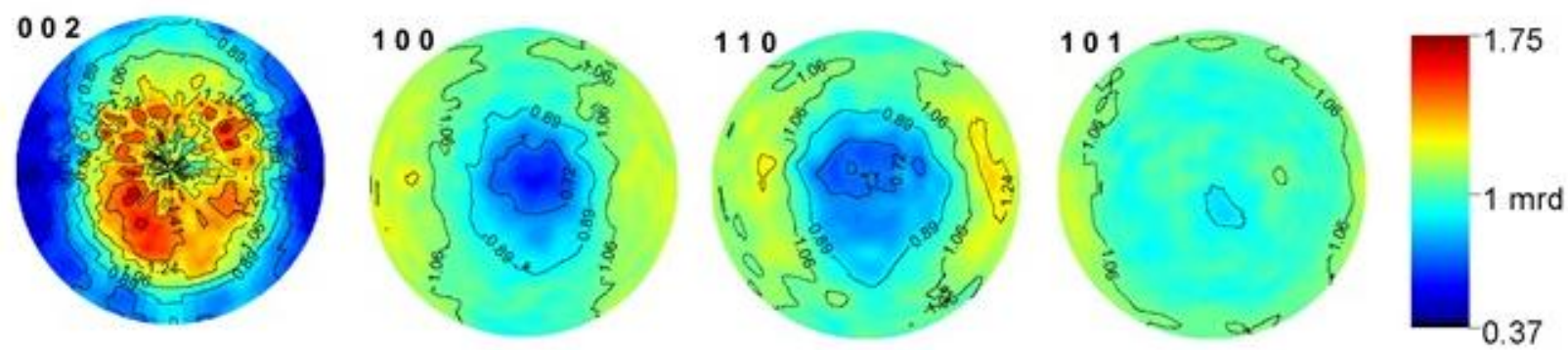

(a)
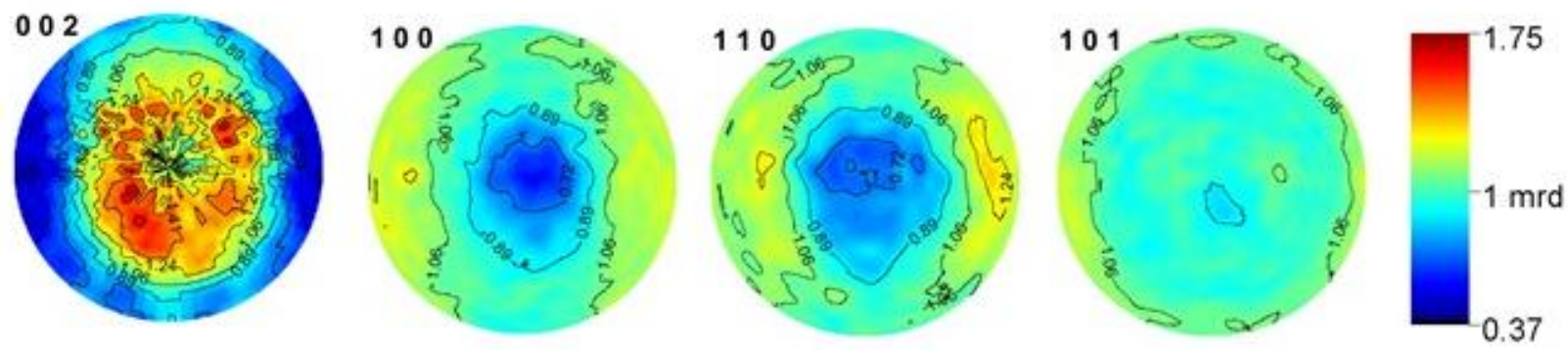

(b)
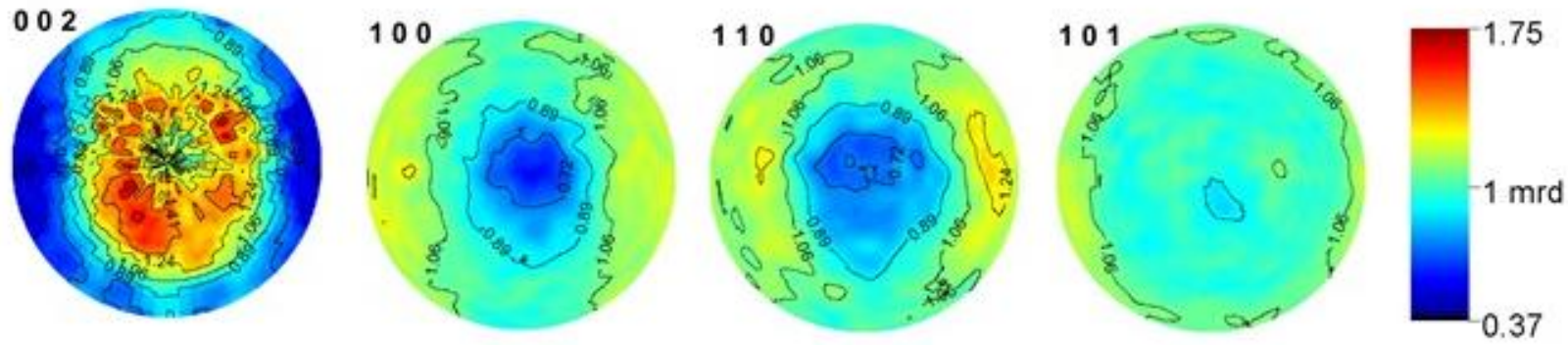

(c)

Figure 6. The measured texture of (a) the as-prepared Ti sample, (b) samples that were compressively deformed to a strain of $30 \%$ and (c) samples that were compressively deformed to a strain of 50\%. (Note that for as-prepared Ti sample, compaction direction corresponds to center of pole figure, radial direction during compaction process corresponds to the radial direction of pole figure. For compressively deformed samples, loading direction corresponds to center of pole figure, compaction and radial directions of sample are labeled in pole figure). 


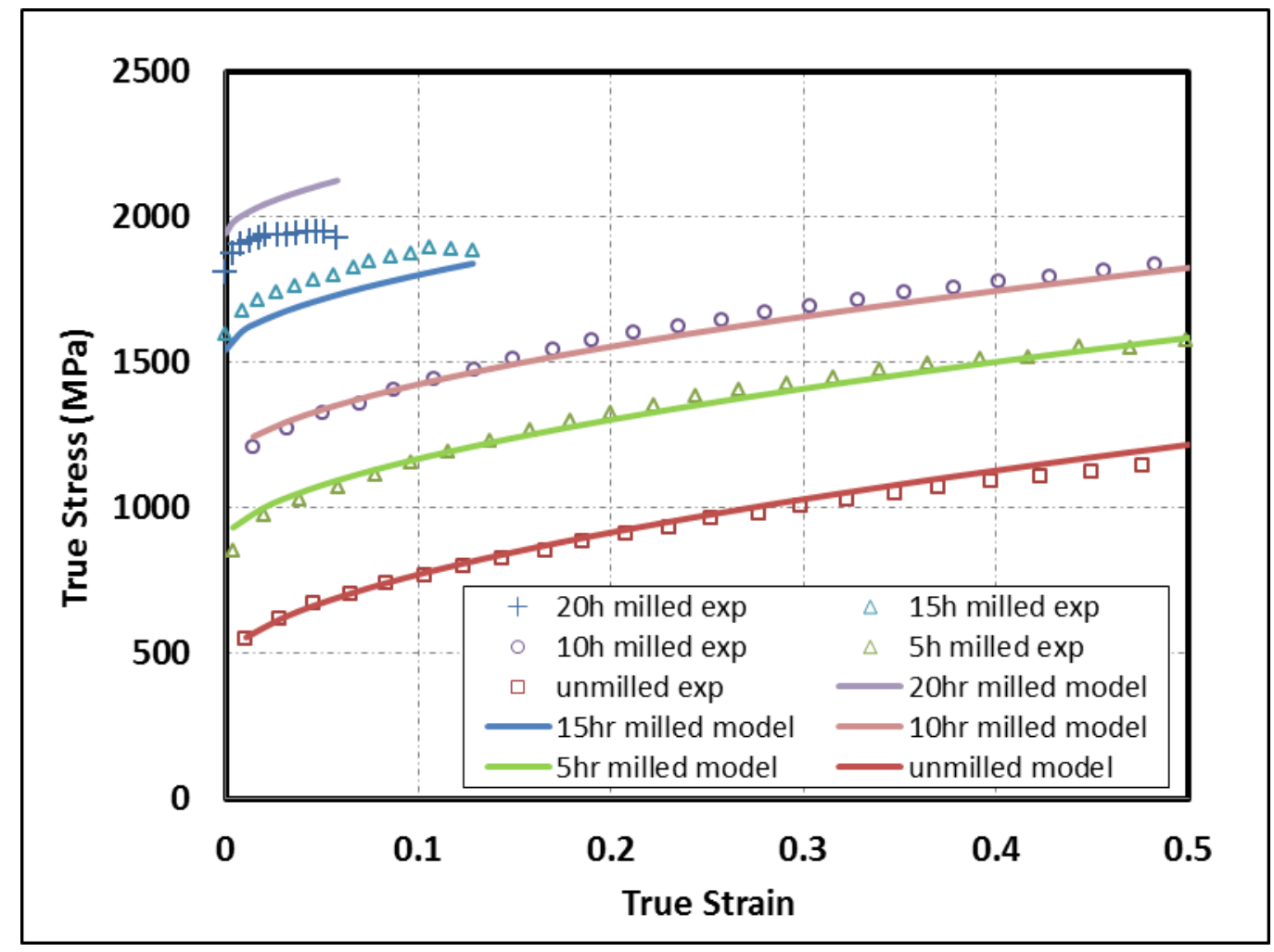

Fig 7. The experimental data along with the model correlations for the ufg/nc Ti made from different milling time powder deformed at RT and a strain rate of $10^{-4} \mathrm{~s}^{-1}$. 


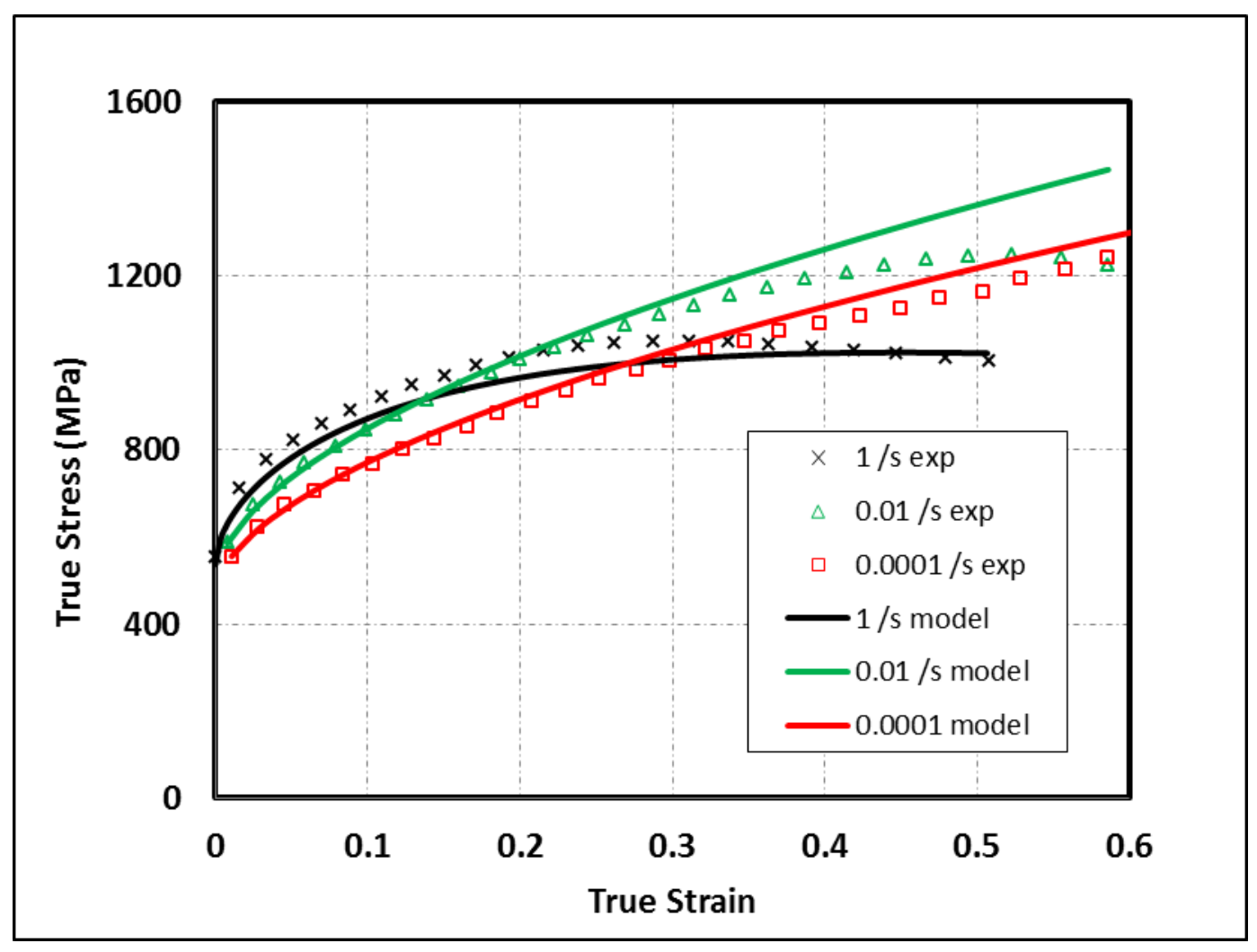

(a)

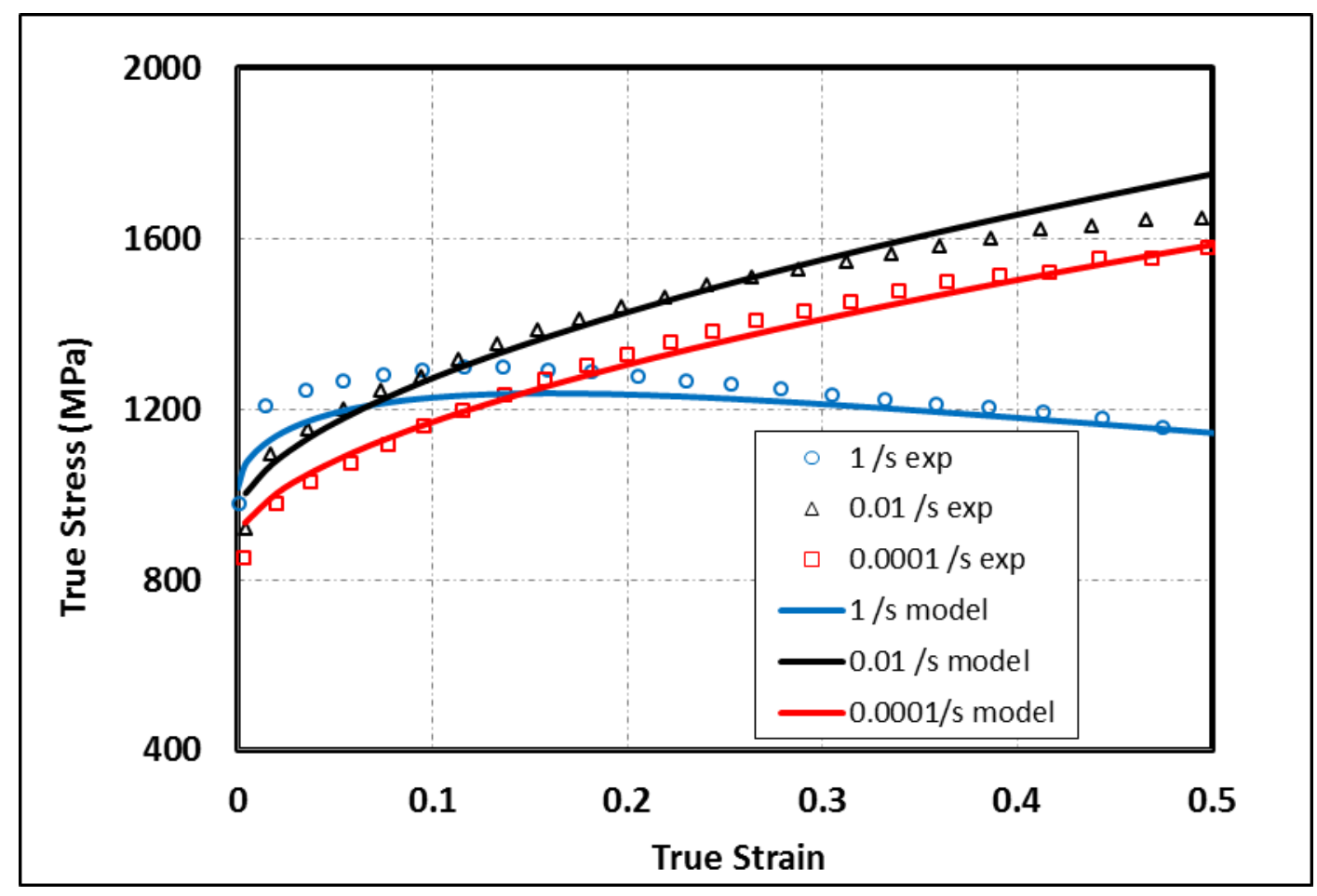

(b) 


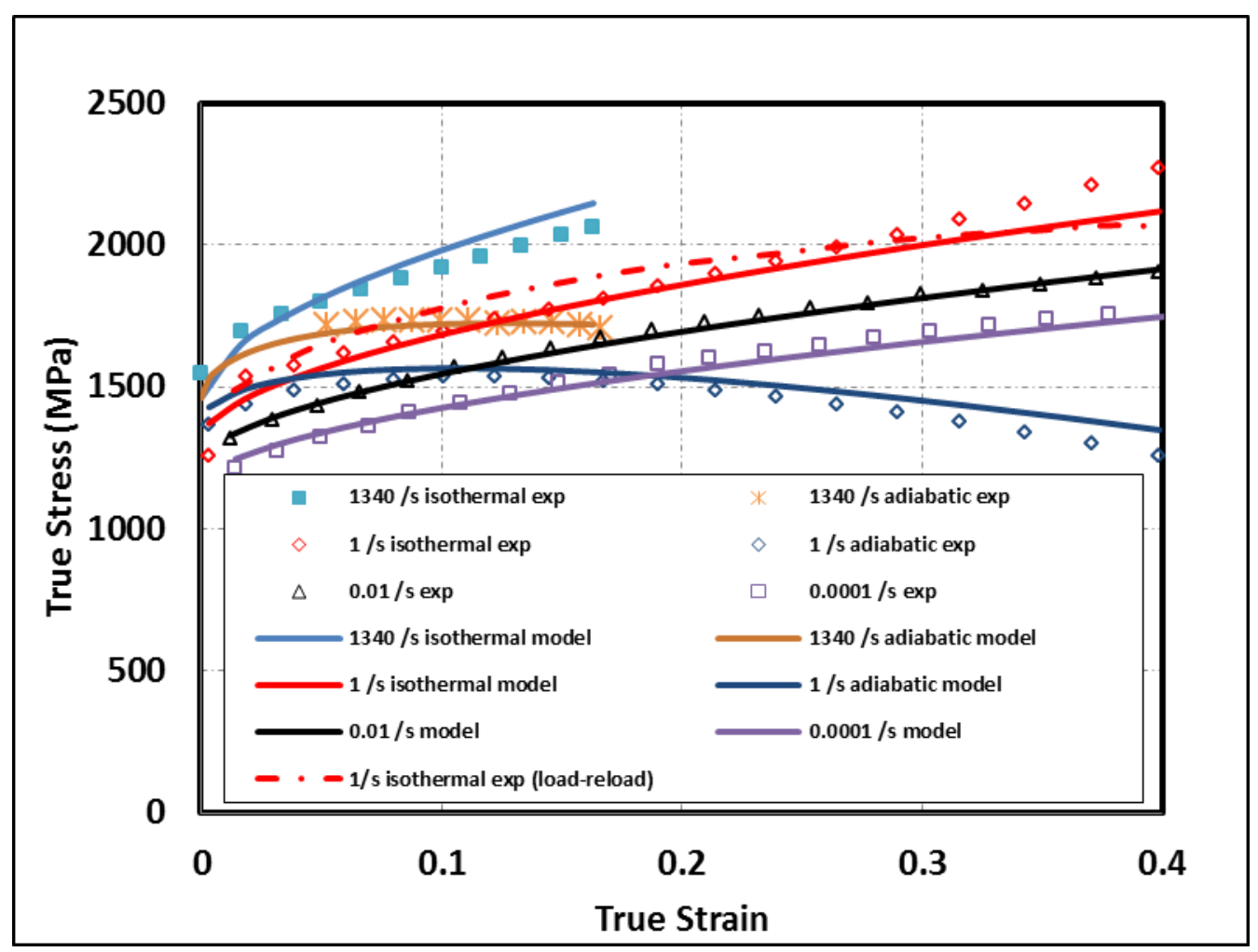

(c)

Figure 8. The experimental data along with the model correlations for the samples made from (a) un-milled, (b) $5 \mathrm{~h}$ milled and (c) $10 \mathrm{~h}$ milled powders at RT and different strain rates. 


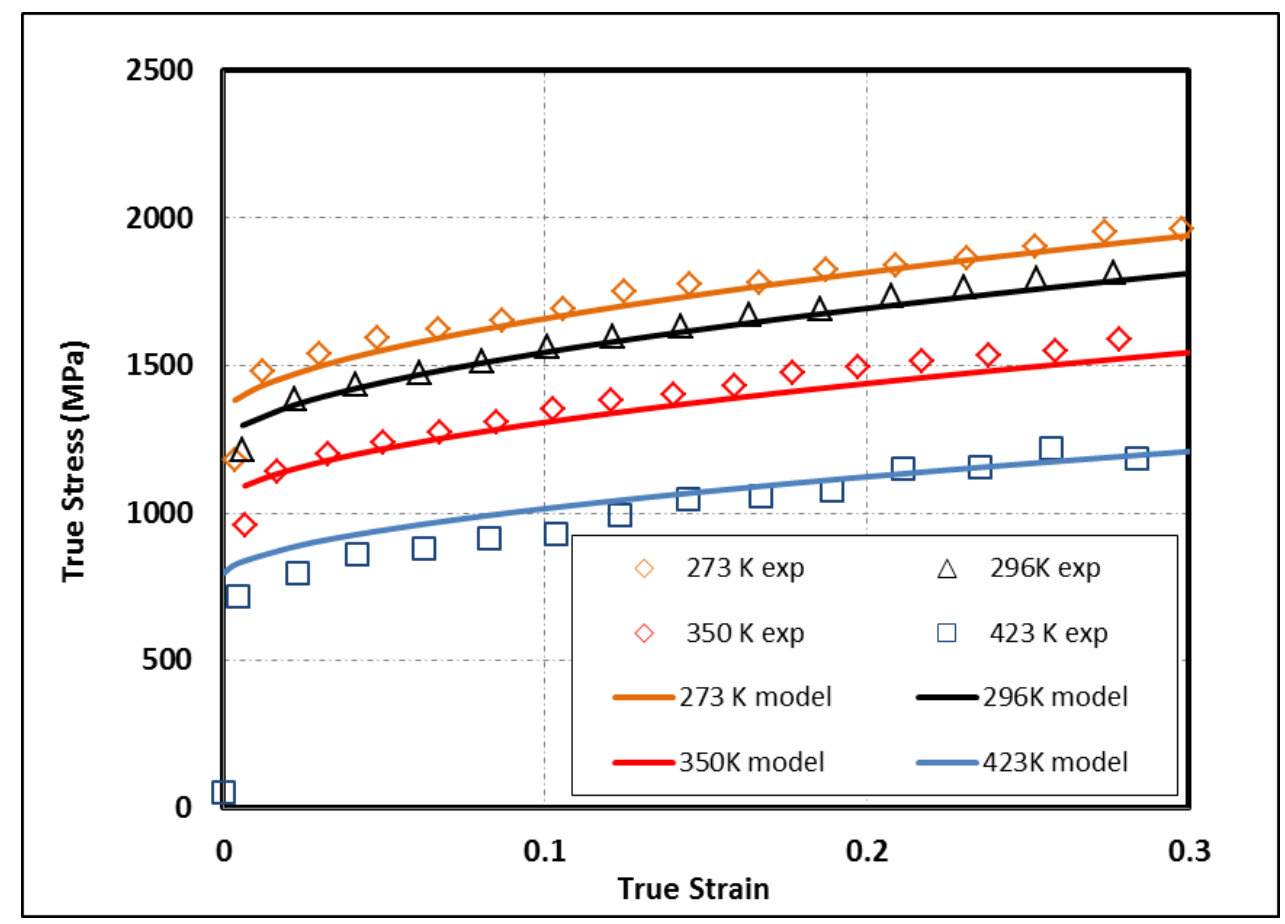

Figure 9. The experimental data along with the model correlations for the $10 \mathrm{~h}$ milled $\mathrm{Ti}$ at different temperatures and at a strain rate of $10^{-2} \mathrm{~s}^{-1}$. 